\title{
The Use of Novel PET Tracers to Image Breast Cancer Biologic Processes Such as Proliferation, DNA Damage and Repair, and Angiogenesis
}

\author{
Laura Kenny \\ Department of Surgery and Cancer, Comprehensive Cancer Imaging Center, Imperial College London, London, United Kingdom
}

The balance between proliferation and cell death is pivotal to breast tumor growth. Because of a combination of environmental and genetic factors leading to activation of oncogenes or inactivation of tumor suppressor genes, these processes become deregulated in cancer. PET imaging of proliferation, angiogenesis, and DNA damage and repair offers the opportunity to monitor therapeutic efficacy to detect changes in tumor biology that may precede physical size reduction and simultaneously allows the study of intratumoral and intertumoral heterogeneity.

This review examines recent developments in breast cancer imaging using novel probes. The probes discussed here are not licensed for routine use and are at various stages of development ranging from preclinical development (e.g., the DNA repair marker $\mathrm{yH} 2 \mathrm{AX}$ ) to clinical validation in larger studies (such as the proliferation probe $3^{\prime}$-deoxy-3'-18 F-fluorothymidine $\left.\left[{ }^{18} \mathrm{~F}-\mathrm{FLT}\right]\right)$. In breast cancer, most studies have focused on proliferation imaging mainly based on ${ }^{18} \mathrm{~F}$-labeled thymidine analogs. Initial studies have been promising; however, the results of larger validation studies are necessary before being incorporated into routine clinical use. Although there are distinct advantages in using process-specific probes, properties such as metabolism need careful consideration, because high background uptake in the liver due to glucuronidation in the case of ${ }^{18} \mathrm{~F}-\mathrm{FLT}$ may limit utility for imaging of liver metastases.

Targeting angiogenesis has had some success in tumors such as renal cell carcinoma; however, angiogenesis inhibitors have not been particularly successful in the clinical treatment of breast cancer. This could be potentially attributed to patient selection due to the lack of validated predictive and responsive biomarkers; the quest for a successful noninvasive biomarker for angiogenesis could solve this challenge. Finally, we look at cell death including apoptosis and DNA damage and repair probes, the most well-studied example being ${ }^{18} \mathrm{~F}$-annexin $\mathrm{V}$; more recently, probes that target caspase endoproteases have been developed and are undergoing early clinical validation studies.

Further clinical studies including analysis of test-retest variability are essential to determine sensitivity and future utility of these probes in breast cancer.
Key Words: PET; proliferation; breast cancer; DNA damage and repair; angiogenesis; FLT

J Nucl Med 2016; 57:89S-95S

DOI: 10.2967/jnumed.115.157958

$\mathbf{T}$ he balance between cell proliferation and cell death is crucial for tumor survival. Although breast cancer treatments are becoming more sophisticated, to allow for precise targeting of specific alterations in tumor cells, the ultimate goal of all anticancer therapies remains the same: to diminish tumor proliferation and increase tumor cell death. Because of the lack of specificity of ${ }^{18} \mathrm{~F}$-FDG for detection of selective targets and effect of benign processes such as inflammation, investigators have developed novel PET biomarkers that may in the future help select patients for therapy and be accurate early predictive indicators of disease response (1). The probes in this section remain at relatively early stages of clinical development and are not in routine clinical use, because they require further validation in larger clinical studies.

Over recent years, there has been a rapid expansion in our knowledge of the molecular biology of breast cancer; this has resulted in the identification of new therapeutic targets and improvements in the long-term survival of cancer patients (2). The probes here are proposed to capture events downstream of well-known signaling cascades such as via estrogen receptor (ER) and human epidermal growth factor receptor 2 . Of the various topics included here, proliferation imaging is the most advanced, and most studies have concentrated on thymidine analogs as surrogates for DNA synthesis. Changes in uptake may reflect antitumor activity, which would otherwise not be detected by standard anatomic techniques as some newer therapies may be cytostatic and therefore not cause a rapid change in tumor volume (3), rendering anatomic response assessment criteria such as RECIST inappropriate $(3,4)$. The high costs of novel tracer development, together with the ever-changing priorities of pharma, often result in probes being abandoned before even reaching the clinical validation stage.

\section{BREAST CANCER PROLIFERATION PROBES}

Thymidine is the only nucleotide incorporated into DNA but not RNA, therefore most proliferation markers have concentrated mainly on thymidine analogs, because theoretically these should provide a reliable surrogate measure for DNA but not RNA synthesis. Thymidine is a substrate for thymidine kinase 1 (TK1), 
E.C. 2.7.1.21, and therefore a marker of activity of the thymidine salvage pathway. Proliferation measurements in breast cancer are normally performed using immunohistochemistry for the Ki-67 labeling index; criteria for assessment exist, but there is considerable variability between different laboratories and measurements could be affected by tumor heterogeneity $(5,6)$.

${ }^{2-}{ }^{11} \mathrm{C}$-thymidine was one of the first proliferation probes. Promising results were seen in early studies, however, this probe has generally been abandoned because of the short half-life of ${ }^{11} \mathrm{C}$, its rapid metabolism, and complex modeling analysis that is required (7-11). Second-generation probes using ${ }^{18} \mathrm{~F}$ have been developed, and these are shown diagrammatically in Figure $1(12,13)$. Most experience has been with $3^{\prime}$-deoxy- $3^{\prime}-{ }^{18} \mathrm{~F}$-fluorothymidine $\left({ }^{18} \mathrm{~F}\right.$ FLT). Transport of ${ }^{18} \mathrm{~F}$-FLT into the cell occurs via passive diffusion and by the equilibrative nucleoside transporter (ENT1), which is expressed in higher numbers in response to drugs such as 5-fluorouracil (which act to inhibit thymidylate synthase, thereby increasing the activity of the salvage pathway) (Fig. 2) (14). Reduced expression of the human ENT1 transporter in breast cancer was found to be associated with poor clinical outcome and prognosis (15). Knockout of the tumor suppressor gene p53 in cells reduces sensitivity to radiation and is associated with increased ${ }^{3} \mathrm{H}$-FLT uptake, increased cells in S-phase, and increased TK1 activity (16). FLT is not a substrate for thymidine phosphorylase, but competing thymidine is, and this may go some way to explain why thymidine phosphorylase expression is related to FLT uptake.

Shields et al. performed the first ${ }^{18}$ F-FLT PET study in a patient with non-small cell lung cancer (17). Correlation with immunohistochemistry measures of proliferation such as Ki-67 has been shown for several tumor types including breast cancer $(18-20)$. The limitations of ${ }^{18}$ F-FLT PET are in imaging the liver and the bone marrow because ${ }^{18} \mathrm{~F}$-FLT undergoes glucuronidation in the liver, leading to a high background uptake level, and in the bone marrow there is high uptake of ${ }^{18} \mathrm{~F}$-FLT, which is attributed to physiologic proliferation. ${ }^{18} \mathrm{~F}$-FLT does benefit from a favorable metabolism profile, because it is metabolized slowly, with $71 \%$ still present as the parent compound at 90 min after injection (19).

In addition to being a marker of proliferation, very early measurements of ${ }^{18} \mathrm{~F}$-FLT uptake in response to thymidylate synthase (TYMS) inhibitors such as capecitabine may represent a pharmacodynamic readout of this pathway, and an initial study suggests

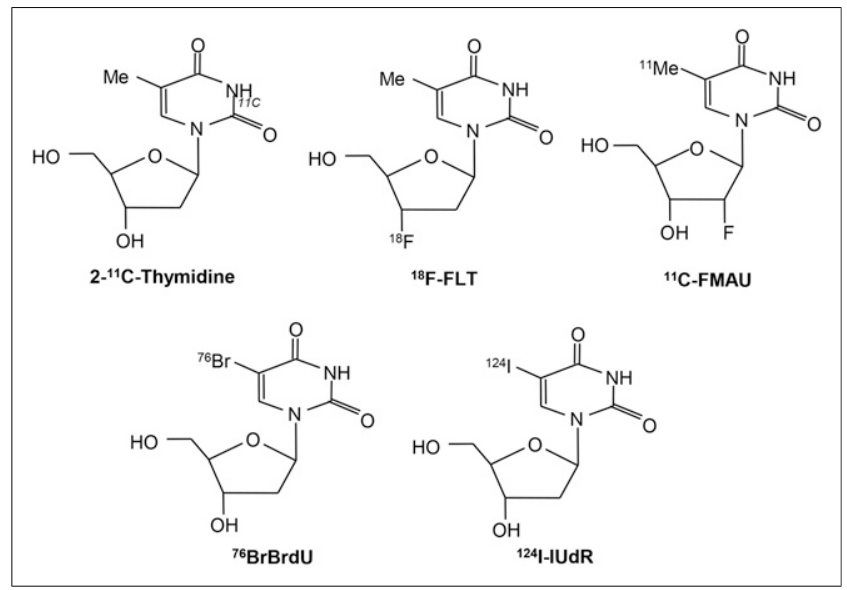

FIGURE 1. Structure of radiolabeled thymidine and related analogs used for imaging proliferation.

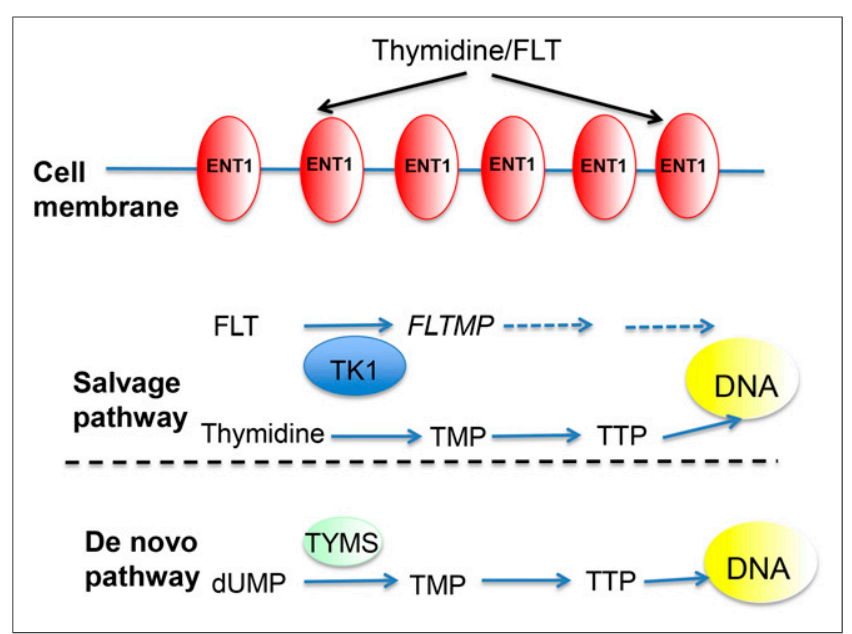

FIGURE 2. Thymidine and ${ }^{18} \mathrm{~F}-\mathrm{FLT}$ transport via ENT1 transporter and thymidine salvage pathway.

that failure to increase ${ }^{18} \mathrm{~F}-\mathrm{FLT}$ at an early time point may be predict resistance (21). Later measurements in studies with longer post-treatment intervals (wk) show decreases in ${ }^{18} \mathrm{~F}$-FLT after various cytotoxic chemotherapy regimens and are thought to reflect a decrease in tumor proliferation. These data are summarized in Table 1. A representative image of ${ }^{18}$ F-FLT before and $1 \mathrm{wk}$ after the first cycle of breast cancer chemotherapy is shown in Figure 3. To date, the number of patients in these studies remains small; more definitive answers should come from the several studies that are currently under way to assess the utility of ${ }^{18} \mathrm{~F}$-FLT response assessment to both chemotherapy and endocrine therapy (www. clinicaltrials.gov). Studies have shown that ${ }^{18}$ F-FLT uptake is repeatable in both breast and lung cancers $(22,23)$. Sohn et al. found that a reduction of greater than $10.9 \%$ for FLT SUV $\max$ could be used to predict therapeutic tumor response (23).

1-(2'-deoxy-2'-fluoro-b-D-arabinofuranosyl) thymine (FMAU) is another thymidine analog that has been developed for use in PET studies. One study of various tumors showed good tumor-tonormal-tissue ratios, with an average SUV in breast cancer of 2.17; low uptake was noted in the bone marrow, but there was physiologic uptake noted in the liver (24). In preclinical studies, FMAU uptake was 5-10 times lower in highly proliferating tumors such as triple-negative breast cancer than ${ }^{18} \mathrm{~F}-\mathrm{FLT}$, and this was attributed to FMAU being a preferential substrate for thymidine kinase 2 compared with TK1 (25). Unlike TK1, thymidine kinase 2 is constitutively expressed and independent of the cell cycle, whereas TK1 is increases in G1/S phase (26).

Novel ${ }^{18}$ F-benzamide analogs, which bind to sigma $2(\sigma 2)$ receptors, are also being developed as proliferation probes and have just completed first-in-patient studies. The precise physiologic function of these receptors is being evaluated but is thought to relate to potassium and calcium ion channel transport; density of $\sigma 2$ receptors is higher in proliferating than nonproliferating cells, in some cases up to 10 -fold. In a preclinical breast cancer model, expression of $\sigma 2$ receptors was related solely to proliferation (27). The $\sigma 2$ receptor binding site is thought to be located in the progesterone receptor membrane component 1 (28). Shoghi et al. have assessed ${ }^{18} \mathrm{~F}$-ISO-1 in 2 rodent models of breast cancer, with uptake correlating with proliferation (measured by bromodeoxyuridine) and growth rate (measured by MR) (28). 
TABLE 1

Clinical Trials Involving ${ }^{18} \mathrm{~F}-\mathrm{FLT}$ PET in Breast Cancer

\begin{tabular}{|c|c|c|c|}
\hline Treatment & $\begin{array}{l}\text { No. of } \\
\text { patients }\end{array}$ & Time point & Outcome \\
\hline Chemotherapy & 14 & Baseline, 6 wk, 30 wk & Early response predicted late response (73) \\
\hline $\begin{array}{l}\text { Chemotherapy } \\
\text { (FEC) }\end{array}$ & 14 & 2 at baseline, then 1 at day 7 & $\begin{array}{l}{ }^{18} \mathrm{~F}-\mathrm{FLT} \text { uptake was repeatable in breast tumors, all } \\
\text { chemotherapy responders had }{ }^{18} \mathrm{~F} \text {-FLT PET response (22) }\end{array}$ \\
\hline Docetaxel & 20 & Baseline, 2 wk & $\begin{array}{l}\text { Early reductions were seen in }{ }^{18} \mathrm{~F}-\mathrm{FLT} \text { uptake, which } \\
\text { were predictive of clinical response }(74)\end{array}$ \\
\hline Capecitabine & 6 & Baseline, $1 \mathrm{~h}$ & $\begin{array}{l}\text { Pharmacodynamic study showing changes in tumor tissue } \\
{ }^{18} \mathrm{~F}-\mathrm{FLT} \text { uptake could be useful as a surrogate measure } \\
\text { of TS inhibition ( } 21)\end{array}$ \\
\hline $\begin{array}{l}\text { Chemotherapy } \\
\text { (FEC or FEC-T) }\end{array}$ & 17 & Baseline, before second cycle & $\begin{array}{l}\text { Baseline, after chemotherapy, or change in SUV } \text { max }_{\text {did not }} \\
\text { correlate with pathologic response to chemotherapy. } \\
\text { Baseline SUV } \text { max }_{\text {mid correlate with Ki-67 (20) }}\end{array}$ \\
\hline $\begin{array}{l}\text { Chemotherapy } \\
\text { (AT-CMF) }\end{array}$ & 15 & $\begin{array}{l}\text { Baseline, after } 1 \text { cycle, and at } \\
\text { the end of chemotherapy }\end{array}$ & $\begin{array}{l}\text { Change in primary tumor } \text { SUV }_{\max } \text { after } 1 \text { cycle was able to } \\
\text { predict residual cancer burden }(75)\end{array}$ \\
\hline
\end{tabular}

FEC = 5-fluorouracil, epirubicin, and cyclophosphamide; TS $=$ thymidylate synthase; AT-CMF = adriamycin, docetaxel, cyclophosphamide, methotrexate, 5-fluorouracil.

Original probes started with ${ }^{11} \mathrm{C}$ labels, and recently Dehdashti et al. explored ${ }^{18} \mathrm{~F}-\mathrm{ISO}-1$ ( $\mathrm{N}$-(4-(6,7-dimethoxy-3,4-dihydroisoquinolin2(1H)-yl)butyl)-2-(2- ${ }^{18} \mathrm{~F}$-fluoroethoxy)-5-methylbenzamide) in a first-in-patient study including 13 patients with breast cancer (29). Tumor $\mathrm{SUV}_{\max }$ and tumor-to-muscle ratio correlated with $\mathrm{Ki}-67$; however, there was no correlation between the tumor-tonormal-tissue uptake ratio and Ki-67. The study revealed high uptake in the liver and pancreas, possibly due to metabolism and receptor density, respectively. A breast cancer-specific study using ${ }^{18} \mathrm{~F}-\mathrm{ISO}-1$ is currently recruiting patients in Pennsylvania and is due to complete in 2018.

\section{CHOLINE}

MR spectroscopy studies in the 1980s revealed altered choline metabolite profiles in tumors (30). Choline is a natural product in the body, an essential component of the phospholipid bilayer in cell membranes, and necessary for fatty acid synthesis (31). Oncogenic transformation of mammary epithelial cells with the erbb2 (human epidermal growth factor receptor 2) oncogene results in altered choline metabolism (32). CTL1 and OCT3 transport choline intracellularly, where it becomes phosphorylated by the enzyme choline kinase $\alpha$ (CHK, E.C. 2.7.1.32) using adenosine triphosphate as a phosphate donor to form phosphocholine and is then metabolized to phosphatidylcholine via cytidine diphosphatecholine in the Kennedy pathway. In patients, CHK activity is increased by $38.5 \%$ in tumor compared with normal tissue and correlates with tumor grade (33). CHK is essential for heregulininduced growth of breast cancer cells, and inhibition of CHK in tumor cells by the specific inhibitor MN58b leads to apoptosis (34). Most clinical studies have been in prostate cancer; however, promising results using ${ }^{11} \mathrm{C}$-choline have been reported in breast cancer patients, in which tumor uptake was reproducible and inhibition of mitogen-activated protein kinase by trastuzumab decreased uptake (Fig. 4) (35). ${ }^{11} \mathrm{C}$-choline and ${ }^{18}$ F-FLT PET uptake were compared in 21 patients with ER-positive breast cancer, and a correlation between both tracers and with Ki-67 was found. Physiologic liver uptake may limit the ability to study liver metastases.

Recent developments include ${ }^{18} \mathrm{~F}$-fluoroethylcholine (36) and dueterated choline analogs ${ }^{18} \mathrm{~F}$-fluoro-[1,2- (2) H(4)]choline $\left({ }^{18} \mathrm{~F}\right.$ D4-choline and ${ }^{11} \mathrm{C}$-D4-choline); preclinical studies suggest that the compounds have similar sensitivities for tumor detection. ${ }^{18} \mathrm{~F}-$ D4-choline is more resistant to metabolism to betaine than the other 2 compounds, which may enable future clinical imaging studies without metabolite correction (37-39). Initial radiodosimetry and biodistribution studies in healthy volunteers showed that ${ }^{18}$ F-D4-choline undergoes renal and hepatobiliary excretion (40); these fluorinated compounds have yet to be assessed in breast cancer.

\section{ACETATE}

Under metabolic stress, cancer cells switch from glucose to acetate as the main nutrient to provide lipids and fatty acids, and breast cancers are sensitive to fatty acid synthesis inhibition $(41,42)$. Acetate is transported into cancer cells via monocarboxylate transporters and is ligated with Co-A by acetyl-CoA synthetase (ACSS, EC 6.2.1.1), forming acetyl-CoA, which can subsequently be used to synthesize cholesterol and fatty acids; alternatively acetate can undergo oxidation in mitochondria via the tricarboxylic acid cycle to $\mathrm{CO}_{2}$ and $\mathrm{H}_{2} 0$. ACSS2 is upregulated in breast cancers in hypoxia, and $40 \%$ of invasive ductal carcinomas express ACSS2 (41). ${ }^{11} \mathrm{C}$-acetate has been explored mainly in prostate cancer, although it may be useful for detecting breast cancer liver metastases (43). ACSS inhibitors are being developed as well as ${ }^{18} \mathrm{~F}$-fluoroacetate; however, there is a lack of evidence for these probes in breast cancer. In addition, acetate uptake may not be specific, because acetate is used for protein acetylation (41). Further research needs to determine the relationship between acetate uptake and physiologic functions within the cell. 


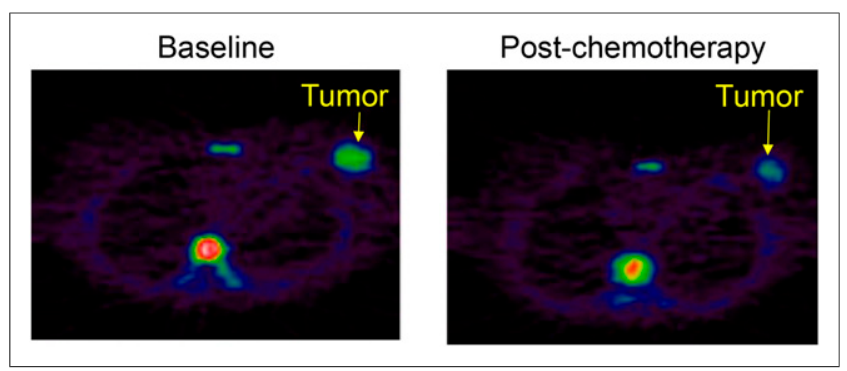

FIGURE 3. ${ }^{18} \mathrm{~F}-\mathrm{FLT}$ PET images of grade 3 invasive ductal breast carcinoma (arrow) with scans obtained at baseline and $10 \mathrm{~d}$ after FEC chemotherapy. High uptake is also seen in vertebral bone marrow at baseline, reflecting physiologic proliferation, and decreased at $10 \mathrm{~d}$, reflecting hematologic effects of chemotherapy.

\section{AMINO ACIDS}

Protein synthesis is essential for cell survival and is upregulated in cancer. The main amino acid that has been used for PET studies is methionine labeled with ${ }^{11} \mathrm{C}$, as L-methyl- ${ }^{11} \mathrm{C}$-methionine $\left({ }^{11} \mathrm{C}\right.$ $\mathrm{MET}$ ), because of its ease of synthesis and high radiochemical yields. Analysis of ${ }^{11} \mathrm{C}$-MET uptake is complicated by the number of nonprotein metabolites. Only limited data relate to clinical studies in breast cancer, including a study of 13 metastatic breast cancer patients in which patients were scanned after 1 mo of endocrine therapy or combination chemotherapy, where reductions in uptake were seen in responding patients, but the numbers of patients were too small to be definitive (44-46). Most studies that have been performed in brain tumors, also for those in which the physiologic uptake in the bone marrow was studied, may limit the ability of ${ }^{11} \mathrm{C}$-MET PET for imaging metastatic disease. In addition, radiolabeled tyrosine $\left(\mathrm{L}^{-11} \mathrm{C}\right.$-tyrosine and ${ }^{18}$ F-fluoroethyltyrosine) and the SPECT tracer ${ }^{3-123}$ I-iodo$\alpha$-methyltyrosine have been developed. Whether uptake truly reflects protein synthesis or amino acid transport via the $\mathrm{L}$ system needs to be considered. More recently, $(4 S)-4-\left(3-{ }^{18} \mathrm{~F}\right.$-fluoropropyl)l-glutamate ( ${ }^{18} \mathrm{~F}$-FSPG), a novel ${ }^{18} \mathrm{~F}$-labeled glutamate derivative for PET imaging, was used to study the $\mathrm{x}_{\mathrm{c} \text { - }}$ transporter, which exchanges cysteine in exchange for glutamate, in breast cancer patients and non-small cell lung cancer patients. Although ${ }^{18} \mathrm{~F}-\mathrm{FSPG}$ uptake was demonstrated in 3 of 5 breast cancer lesions, the 2 that were missed were over $7 \mathrm{~cm}$ in size; thus, the importance of molecular subtype of breast cancer in relation to ${ }^{18}$ F-FSPG uptake needs to be determined (47).

So far the probes discussed image cell growth and synthetic functions; the nature of the cell microenvironment is also crucial for cell survival.

\section{ANGIOGENESIS}

Folkman characterized angiogenesis as being fundamental for tumor growth beyond $2 \mathrm{~mm}$ in 1971 (48). Since then, our understanding of the molecular biology of angiogenesis has advanced significantly, leading to the development of licensed therapeutic agents. Surprisingly, in the clinic there is no validated predictive biomarker for the selection of antiangiogenic therapy (49). Agents that target angiogenesis can be divided into 3 categories: those that prevent binding of growth factors to their receptors, such as the vascular endothelial growth factor-neutralizing antibody bevacizumab; the multitargeted tyrosine kinase inhibitors (such as pazopanib, sunitinib, and sorafenib); and the matrix metalloproteinase inhibitors such as marimistat (50). Bevacizumab was previously approved for breast cancer because of improved progression-free survival, but the Food and Drug Administration later withdrew this indication because of no clear benefit in overall survival (51).

Imaging probes have been directed to targets expressed on or binding to vascular endothelial cells or to the extracellular matrix. ${ }^{89} \mathrm{Zr}$-bevacizumab was used to study 23 patients with breast tumor lesions, patients were imaged $4 \mathrm{~d}$ after administration because of the probe's half-life of $78.4 \mathrm{~h}$, and significant differences were observed between breast tumor and normal breast uptake and also between luminal A and luminal B tumors (luminal B had higher uptake) but the radiotracer was less sensitive for the detection of nodal metastases (only 4 of 10 lesions were detected) (52).

The integrins are heterodimeric proteins that regulate the cellular microenvironment and stroma $(53,54)$. The $\alpha_{v} \beta_{3}$ integrin is involved in angiogenesis and is expressed on newly developing blood vessels and some tumor cells (55). RGD (arginine-glycineaspartame) peptides are known to bind to the $\alpha_{v} \beta_{3}$ with high affinity (11 nM), and preclinical models using vascular endothelial growth factor inhibitors have shown reduced radiolabeled RGDpeptide after treatment $(56) .{ }^{18} \mathrm{~F}$-fluciclatide (previously named $\left.{ }^{18} \mathrm{~F}-\mathrm{AH} 111585\right)$ is safe and well tolerated, with acceptable dosimetry (57). A study in 7 patients with metastatic breast cancer showed good tumor-to-normal-tissue ratios. Liver lesions were viewed as regions of hypointense uptake due to high background signal, presumably due to physiologic metabolism; areas of heterogeneity of uptake were seen in larger lesions with increased peripheral uptake and decreased uptake centrally, in keeping with active tumor growth and necrosis, respectively (Fig. 5) (22).

Beer et al. have studied ${ }^{18} \mathrm{~F}$-galacto-RGD for imaging of the $\alpha_{v} \beta_{3}$ integrin, designed with a sugar moiety to enhance excretion; promising results were seen in breast cancer and other cancers (58). Uptake of ${ }^{18} \mathrm{~F}$-galacto-RGD correlated with immunohistochemistry for the $\alpha_{\mathrm{v}} \beta_{3}$ integrin and microvessel density in snap-frozen tissue (58). ${ }^{18} \mathrm{~F}$-galacto-RGD synthesis is complex, requiring multiple steps; a second-generation compound, ${ }^{68} \mathrm{Ga}$-NODAGATHERANOST, has been assessed in 2 patients, one of whom had breast cancer,

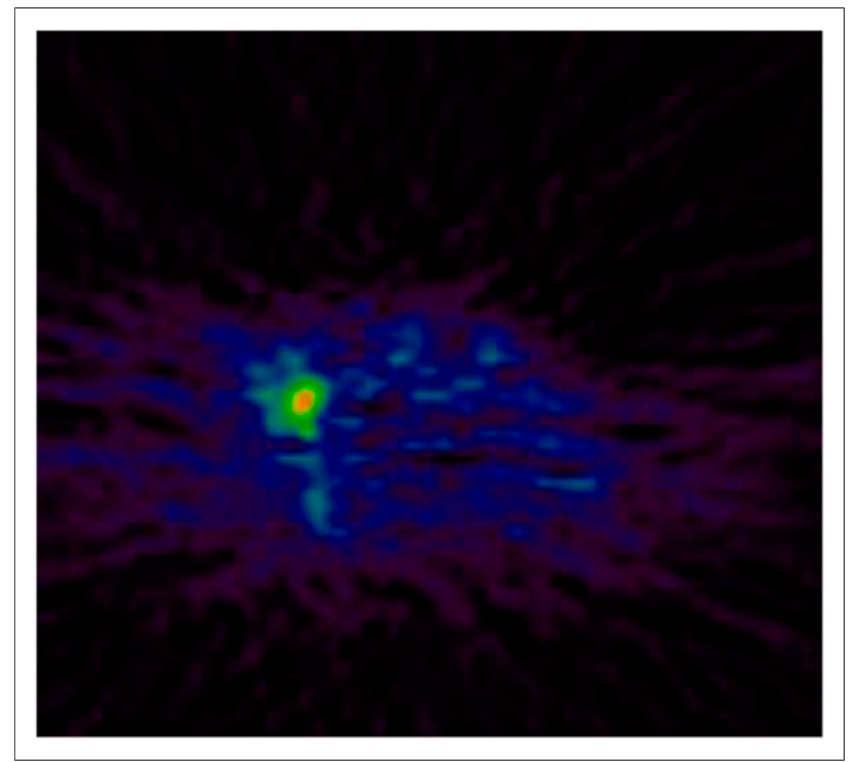

FIGURE 4. ${ }^{11} \mathrm{C}$-choline PET image of cervical lymph node metastasis from breast cancer. 

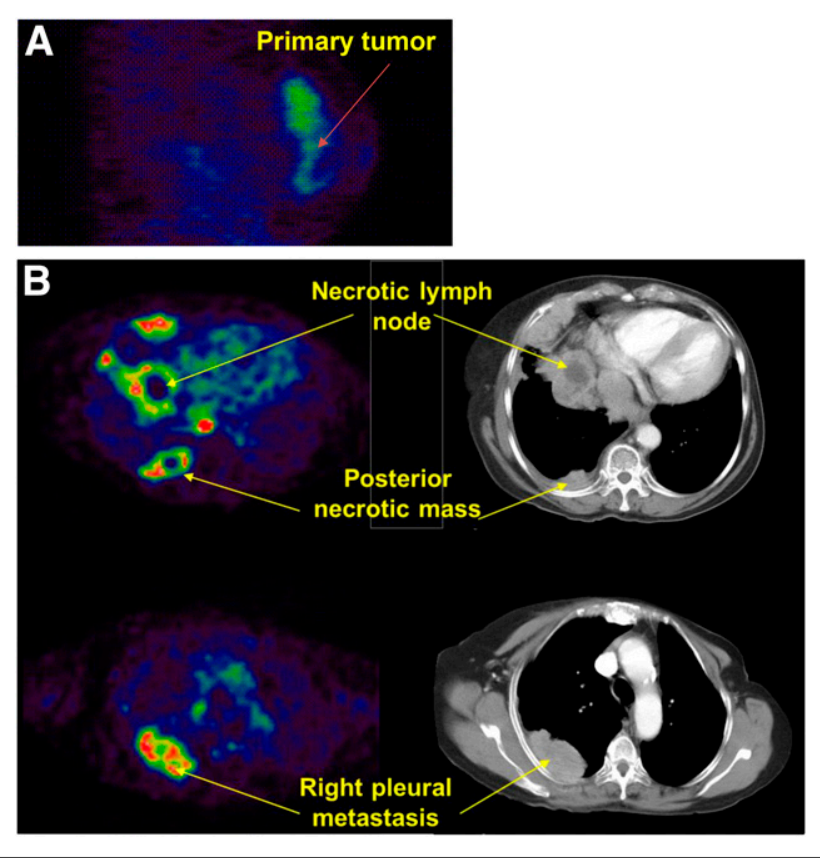

FIGURE 5. ${ }^{18} \mathrm{~F}$-fluciclatide PET images of metastatic breast cancer.

and shows some promise (59). For ${ }^{18}$ F-FPPRGD2, which was recently developed by the Gambhir group to study $\alpha_{\mathrm{v}} \beta_{3}$ integrin expression and compared with ${ }^{18} \mathrm{~F}$-FDG uptake in 8 patients with breast cancer, high specificity was seen, although high liver and renal uptake were seen due to metabolism and excretion (60).

\section{HYPOXIA IMAGING}

Hypoxia in breast cancer cells may support the acquisition of the stem cell phenotype (61) and for many years has been attributed as a major factor to resistance to both chemotherapy and radiotherapy (62). Tumor hypoxia develops as result of poor arteriolar supply, high $\mathrm{O}_{2}$ consumption rate, disorganized tumor vasculature, slow blood flow, and vascular shunting. In many tumors, these are associated with upregulation of hypoxia-inducible factor-1 $\alpha$, which stimulates several downstream targets, resulting in increased glycolysis, angiogenesis, and resistance to apoptosis.

Hypoxia imaging has focused mainly on radiolabeled nitroimidazoles; relatively few studies have been performed in breast cancer, as most have involved brain tumors using ${ }^{18} \mathrm{~F}$-misonidazole $\left({ }^{18} \mathrm{~F}-\mathrm{FMISO}\right)$. A recent study compared ${ }^{18} \mathrm{~F}-\mathrm{FDG}$ and ${ }^{18} \mathrm{~F}-\mathrm{FMISO}$ PET in postmenopausal women with stage II-IV ER $\alpha$-positive breast cancer before and after 3 mo of treatment with the aromatase inhibitor letrozole. ${ }^{18} \mathrm{~F}$-FMISO was superior to ${ }^{18} \mathrm{~F}-\mathrm{FDG}$ in predicting resistance to endocrine therapy; this study did not show a correlation between tumor hypoxia-inducible factor-1 $\alpha$ and uptake of ${ }^{18}$ F-FMISO (63). The disadvantages of ${ }^{18}$ F-FMISO PET include a long biologic half-life, imaging 2-3 h after radiotracer injection, metabolism, and slow clearance from the blood (63).

Second-generation compounds including ${ }^{18} \mathrm{~F}$-fluoroazomycin arabinoside, which is more hydrophilic than ${ }^{18} \mathrm{~F}$-FMISO, and ${ }^{18} \mathrm{~F}$-2-nitroimidazol-pentafluoropropyl acetamide, which is more lipophilic, have been developed (64), as has the nonnitroimidazole compound copper(II)diacetyl-bisN (4)-methylthiosemicarbazone $(\mathrm{Cu}-\mathrm{ATSM})$, which can be labeled with either ${ }^{60} \mathrm{Cu}$ or
${ }^{64} \mathrm{Cu}$, but so far none has been explored in breast cancer (64). Lysl oxidase expression correlates with tissue hypoxia, and a new ${ }^{18} \mathrm{~F}$-labeled probe has been developed and studied in ERpositive and triple-negative breast tumor xenografts with good results (65).

\section{DNA DAMAGE}

DNA double-strand breaks (DSBs) are lethal, and detection of DSBs is useful for detection of cell death. After a DSB induced by exogenous or endogenous DNA damage, the protein $\mathrm{H} 2 \mathrm{AX}$ becomes phosphorylated by kinases, such as ataxia-telangiectasia mutated in the PI3K pathway, in the first step of the DNA repair process, forming $\gamma \mathrm{H} 2 \mathrm{AX}$ complexes in a $1: 1$ ratio to DSBs. Antibodies to $\gamma \mathrm{H} 2 \mathrm{AX}$ labeled with fluorescent probes are commonly used for laboratory assays of cell death. ${ }^{111} \mathrm{In}$-anti- $\gamma \mathrm{H} 2 \mathrm{AX}$-TAT immunoconjugate was used as a SPECT probe for detecting DNA damage in mice during mammary oncogenesis and showed changes before MR imaging (66). ${ }^{89} \mathrm{Zr}$-anti- $\gamma \mathrm{H} 2 \mathrm{AX}$-TAT immunoconjugates have also shown promising results in a preclinical breast cancer model with 8-fold-higher uptake in irradiated $\gamma \mathrm{H} 2 \mathrm{AX}$ cells than nonirradiated controls (67).

\section{APOPTOSIS}

Imaging apoptosis may be a useful biomarker of drug sensitivity or resistance. Most experience is with radiolabeled annexin V, which detects phosphatidylserine expression on the cell surface where it has transferred from the cytoplasmic surface of the cell membrane. However, this process is not unique to apoptosis and can occur in other forms of cell death; even in apoptosis, some cell lines do not express phosphatidylserine $(68,69)$. Other disadvantages include slow clearance, leading to high background due to the large size $(36 \mathrm{kDa}) .{ }^{18} \mathrm{~F}$-annexin $\mathrm{V}$ showed a 3 - to 10 -fold rise in liver cells, which correlated with histologic measures of apoptosis using a terminal deoxynucleotidyl transferase assay (70). Lower-molecular-weight probes, including ${ }^{18} \mathrm{~F}$-labeled 2-(5-fluoro-pentyl)-2-methyl-malonic acid (ML-10), that undergo selective membrane binding and intracellular transport, have been developed, and these are thought to be selective for apoptosis; further efforts are necessary to determine their specific applications to breast cancer (71).

Caspases are cysteine aspartate-specific proteases activated by the intrinsic and extrinsic apoptotic pathways. The executioner caspases 3 and 7 have been sought as imaging probes. Isatin sulfonamides bind to caspase 3 and 7 with nanomolar affinity, and a new ${ }^{18} \mathrm{~F}$-labeled probe, ${ }^{18} \mathrm{~F}$-ICMT-11, correlates with cellular caspase 3 activation in vitro. A healthy volunteer study has shown acceptable radiation dosimetry, with predominantly hepatobiliary and renal excretion; a current study is now assessing the effects of chemotherapy on ${ }^{18} \mathrm{~F}$-ICMT-11 uptake in breast cancer (72).

Other tracers in the pipeline include ${ }^{18} \mathrm{~F}$-fluorobenzyl triphenylphosphonium, a voltage sensor detector for mitochondrial dysfunction during apoptosis.

\section{CONCLUSION}

PET is useful for studying proliferation in breast cancer using thymidine analogs such as FLT and shows promise for imaging of cell death. Probes of angiogenesis, DNA repair, and cell death remain at earlier stages of development and require validation in patients. Factors such as radiotracer metabolism need careful consideration when imaging liver metastases. Further clinical studies 
are now required to compare the utility of these tracers in patients with ${ }^{18} \mathrm{~F}-\mathrm{FDG}$, and to determine their attributes in the various molecular subtypes of breast cancers.

\section{DISCLOSURE}

The costs of publication of this article were defrayed in part by the payment of page charges. Therefore, and solely to indicate this fact, this article is hereby marked "advertisement" in accordance with 18 USC section 1734. Laura Kenny is funded by an NIHR Clinician scientist fellowship (CS09/009). The PET images were provided from studies funded by Professor Eric Aboagye's MRC programme grant and GE Healthcare (fluciclatide). No other potential conflict of interest relevant to this article was reported.

\section{REFERENCES}

1. Buck AK, Schirrmeister H, Mattfeldt T, Reske SN. Biological characterisation of breast cancer by means of PET. Eur J Nucl Med Mol Imaging. 2004;31(suppl 1): S80-S87.

2. Park JH, Anderson WF, Gail MH. Improvements in US breast cancer survival and proportion explained by tumor size and estrogen-receptor status. J Clin Oncol. 2015;33:2870-2876.

3. Eisenhauer EA, Therasse P, Bogaerts J, et al. New response evaluation criteria in solid tumours: revised RECIST guideline (version 1.1). Eur J Cancer. 2009;45: 228-247.

4. Therasse P. Evaluation of response: new and standard criteria. Ann Oncol. 2002;13(suppl 4):127-129.

5. Dowsett M, Nielsen TO, A'Hern R, et al. Assessment of Ki67 in breast cancer: recommendations from the International Ki67 in Breast Cancer working group. J Natl Cancer Inst. 2011;103:1656-1664.

6. Polley MY, Leung SC, McShane LM, et al. An international Ki67 reproducibility study. J Natl Cancer Inst. 2013;105:1897-1906.

7. Mankoff DA, Shields AF, Graham MM, Link JM, Eary JF, Krohn KA. Kinetic analysis of 2-[carbon-11]thymidine PET imaging studies: compartmental model and mathematical analysis. J Nucl Med. 1998;39:1043-1055.

8. Mankoff DA, Shields AF, Krohn KA. PET imaging of cellular proliferation. Radiol Clin North Am. 2005;43:153-167.

9. Mankoff DA, Shields AF, Link JM, et al. Kinetic analysis of $2-\left[{ }^{11} \mathrm{C}\right]$ thymidine PET imaging studies: validation studies. J Nucl Med. 1999;40:614-624.

10. Shields AF, Mankoff D, Graham MM, et al. Analysis of 2-carbon-11-thymidine blood metabolites in PET imaging. J Nucl Med. 1996;37:290-296.

11. Shields AF, Mankoff DA, Link JM, et al. Carbon-11-thymidine and FDG to measure therapy response. J Nucl Med. 1998;39:1757-1762.

12. Shields AF. PET imaging with ${ }^{18} \mathrm{~F}$-FLT and thymidine analogs: promise and pitfalls. J Nucl Med. 2003;44:1432-1434.

13. Shields AF. PET imaging of tumor growth: not as easy as it looks. Clin Cancer Res. 2012;18:1189-1191.

14. Perumal M, Pillai RG, Barthel H, et al. Redistribution of nucleoside transporters to the cell membrane provides a novel approach for imaging thymidylate synthase inhibition by positron emission tomography. Cancer Res. 2006;66:8558-8564.

15. Lane J, Martin TA, McGuigan C, Mason MD, Jiang WG. The differential expression of hCNT1 and hENT1 in breast cancer and the possible impact on breast cancer therapy. J Exp Ther Oncol. 2010;8:203-210.

16. Rasey JS, Grierson JR, Wiens LW, Kolb PD, Schwartz JL. Validation of FLT uptake as a measure of thymidine kinase-1 activity in A549 carcinoma cells. J Nucl Med. 2002;43:1210-1217.

17. Shields AF, Grierson JR, Dohmen BM, et al. Imaging proliferation in vivo with [F-18]FLT and positron emission tomography. Nat Med. 1998;4:1334-1336.

18. Chalkidou A, Landau DB, Odell EW, Cornelius VR, O'Doherty MJ, Marsden PK. Correlation between Ki-67 immunohistochemistry and ${ }^{18} \mathrm{~F}$-fluorothymidine uptake in patients with cancer: a systematic review and meta-analysis. Eur J Cancer. 2012;48:3499-3513.

19. Kenny LM, Vigushin DM, Al-Nahhas A, et al. Quantification of cellular proliferation in tumor and normal tissues of patients with breast cancer by $\left[{ }^{18} \mathrm{~F}\right]$ fluorothymidine-positron emission tomography imaging: evaluation of analytical methods. Cancer Res. 2005;65:10104-10112.

20. Woolf DK, Beresford M, Li SP, et al. Evaluation of FLT-PET-CT as an imaging biomarker of proliferation in primary breast cancer. Br J Cancer. 2014;110: 2847-2854.
21. Kenny LM, Contractor KB, Stebbing J, et al. Altered tissue $3^{\prime}$-deoxy- $3^{\prime}-\left[{ }^{18} \mathrm{~F}\right]$ fluorothymidine pharmacokinetics in human breast cancer following capecitabine treatment detected by positron emission tomography. Clin Cancer Res. 2009;15:6649-6657.

22. Kenny L, Coombes RC, Vigushin DM, Al-Nahhas A, Shousha S, Aboagye EO. Imaging early changes in proliferation at 1 week post chemotherapy: a pilot study in breast cancer patients with $3^{\prime}$-deoxy- $3^{\prime}-\left[{ }^{18} \mathrm{~F}\right]$ fluorothymidine positron emission tomography. Eur J Nucl Med Mol Imaging. 2007;34:1339-1347.

23. Sohn HJ, Yang YJ, Ryu JS, et al. $\left[{ }^{18} \mathrm{~F}\right]$ Fluorothymidine positron emission tomography before and 7 days after gefitinib treatment predicts response in patients with advanced adenocarcinoma of the lung. Clin Cancer Res. 2008;14:7423-7429.

24. Sun H, Sloan A, Mangner TJ, et al. Imaging DNA synthesis with $\left[{ }^{18} \mathrm{~F}\right] \mathrm{FMAU}$ and positron emission tomography in patients with cancer. Eur J Nucl Med Mol Imaging. 2005;32:15-22.

25. Tehrani OS, Douglas KA, Lawhorn-Crews JM, Shields AF. Tracking cellular stress with labeled FMAU reflects changes in mitochondrial TK2. Eur J Nucl Med Mol Imaging. 2008;35:1480-1488.

26. Hannigan BM, Barnett YA, Armstrong DB, McKelvey-Martin VJ, McKenna PG. Thymidine kinases: the enzymes and their clinical usefulness. Cancer Biother. 1993;8:189-197.

27. Al-Nabulsi I, Mach RH, Wang LM, et al. Effect of ploidy, recruitment, environmental factors, and tamoxifen treatment on the expression of sigma-2 receptors in proliferating and quiescent tumour cells. Br J Cancer. 1999;81:925-933.

28. Shoghi KI, Xu J, Su Y, et al. Quantitative receptor-based imaging of tumor proliferation with the sigma-2 ligand $\left[{ }^{18} \mathrm{~F}\right] \mathrm{ISO}-1$. PLoS One. 2013;8:e74188.

29. Dehdashti F, Laforest R, Gao F, et al. Assessment of cellular proliferation in tumors by PET using ${ }^{18}$ F-ISO-1. J Nucl Med. 2013;54:350-357.

30. Glunde K, Bhujwalla ZM. Metabolic tumor imaging using magnetic resonance spectroscopy. Semin Oncol. 2011;38:26-41.

31. Lewis JS, Laforest R, Dehdashti F, Grigsby PW, Welch MJ, Siegel BA. An imaging comparison of ${ }^{64} \mathrm{Cu}$-ATSM and ${ }^{60} \mathrm{Cu}$-ATSM in cancer of the uterine cervix. J Nucl Med. 2008;49:1177-1182.

32. Aboagye EO, Bhujwalla ZM. Malignant transformation alters membrane choline phospholipid metabolism of human mammary epithelial cells. Cancer Res. 1999;59:80-84.

33. Ramírez de Molina A, Gutierrez R, Ramos MA, et al. Increased choline kinase activity in human breast carcinomas: clinical evidence for a potential novel antitumor strategy. Oncogene. 2002;21:4317-4322.

34. Rodríguez-González A, Ramirez de Molina A, Banez-Coronel M, Megias D, Lacal JC. Inhibition of choline kinase renders a highly selective cytotoxic effect in tumour cells through a mitochondrial independent mechanism. Int J Oncol. 2005;26:999-1008.

35. Kenny LM, Contractor KB, Hinz R, et al. Reproducibility of $\left[{ }^{11} \mathrm{C}\right]$ cholinepositron emission tomography and effect of trastuzumab. Clin Cancer Res. 2010;16:4236-4245.

36. Clary GL, Tsai CF, Guynn RW. Substrate specificity of choline kinase. Arch Biochem Biophys. 1987;254:214-221.

37. Witney TH, Alam IS, Turton DR, et al. Evaluation of deuterated ${ }^{18} \mathrm{~F}$ - and ${ }^{11} \mathrm{C}$ labeled choline analogs for cancer detection by positron emission tomography. Clin Cancer Res. 2012;18:1063-1072.

38. Contractor $\mathrm{K}$, Challapalli A, Barwick T, et al. Use of $\left[{ }^{11} \mathrm{C}\right]$ choline PET-CT as a noninvasive method for detecting pelvic lymph node status from prostate cancer and relationship with choline kinase expression. Clin Cancer Res. 2011;17:76737683.

39. Leyton J, Smith G, Zhao Y, et al. [ $\left.{ }^{18} \mathrm{~F}\right]$ fluoromethyl-[1,2-2H4]-choline: a novel radiotracer for imaging choline metabolism in tumors by positron emission tomography. Cancer Res. 2009;69:7721-7728.

40. Challapalli A, Sharma R, Hallett WA, et al. Biodistribution and radiation dosimetry of deuterium-substituted ${ }^{18} \mathrm{~F}$-fluoromethyl-[1, 2-2H4]choline in healthy volunteers. J Nucl Med. 2014;55:256-263.

41. Wellen KE, Hatzivassiliou G, Sachdeva UM, Bui TV, Cross JR, Thompson CB. ATP-citrate lyase links cellular metabolism to histone acetylation. Science. 2009;324:1076-1080.

42. Schug ZT, Peck B, Jones DT, et al. Acetyl-CoA synthetase 2 promotes acetate utilization and maintains cancer cell growth under metabolic stress. Cancer Cell. 2015;27:57-71.

43. Deford-Watts LM, Mintz A, Kridel SJ. The potential of ${ }^{11} \mathrm{C}$-acetate PET for monitoring the fatty acid synthesis pathway in tumors. Curr Pharm Biotechnol. 2013;14:300-312.

44. Huovinen R, Leskinen-Kallio S, Nagren K, Lehikoinen P, Ruotsalainen U, Teras M. Carbon-11-methionine and PET in evaluation of treatment response of breast cancer. Br J Cancer. 1993;67:787-791. 
45. Jansson T, Westlin JE, Ahlstrom H, Lilja A, Langstrom B, Bergh J. Positron emission tomography studies in patients with locally advanced and/or metastatic breast cancer: a method for early therapy evaluation? J Clin Oncol. 1995;13:1470-1477.

46. Lindholm P, Lapela M, Nagren K, Lehikoinen P, Minn H, Jyrkkio S. Preliminary study of carbon-11 methionine PET in the evaluation of early response to therapy in advanced breast cancer. Nucl Med Commun. 2009;30:30-36.

47. Baek S, Choi CM, Ahn SH, et al. Exploratory clinical trial of (4S)-4-(3-[ $\left.{ }^{18} \mathrm{~F}\right]$ fluoropropyl)-L-glutamate for imaging $\mathrm{xC}$ - transporter using positron emission tomography in patients with non-small cell lung or breast cancer. Clin Cancer Res. 2012;18:5427-5437.

48. Folkman J. Tumor angiogenesis: therapeutic implications. $N$ Engl J Med. 1971;285:1182-1186

49. Wilson PM, LaBonte MJ, Lenz HJ. Assessing the in vivo efficacy of biologic antiangiogenic therapies. Cancer Chemother Pharmacol. 2013;71:1-12.

50. Carmeliet P, Jain RK. Molecular mechanisms and clinical applications of angiogenesis. Nature. 2011;473:298-307.

51. Tanne JH. FDA cancels approval for bevacizumab in advanced breast cancer. BMJ. 2011;343:d7684.

52. Gaykema SB, Brouwers AH, Lub-de Hooge MN, et al. ${ }^{89} \mathrm{Zr}$-bevacizumab PET imaging in primary breast cancer. J Nucl Med. 2013;54:1014-1018.

53. Eliceiri BP, Klemke R, Stromblad S, Cheresh DA. Integrin alphavbeta3 requirement for sustained mitogen-activated protein kinase activity during angiogenesis. J Cell Biol. 1998;140:1255-1263.

54. Varner JA, Cheresh DA. Tumor angiogenesis and the role of vascular cell integrin alphavbeta3. Important Adv Oncol. 1996;69-87.

55. Brooks PC, Clark RA, Cheresh DA. Requirement of vascular integrin alpha v beta 3 for angiogenesis. Science. 1994;264:569-571.

56. Morrison MS, Ricketts SA, Barnett J, Cuthbertson A, Tessier J, Wedge SR. Use of a novel Arg-Gly-Asp radioligand, ${ }^{18} \mathrm{~F}-\mathrm{AH} 111585$, to determine changes in tumor vascularity after antitumor therapy. J Nucl Med. 2009;50:116-122.

57. Kenny LM, Coombes RC, Oulie I, et al. Phase I trial of the positron-emitting Arg-Gly-Asp (RGD) peptide radioligand ${ }^{18} \mathrm{~F}-\mathrm{AH} 111585$ in breast cancer patients. J Nucl Med. 2008;49:879-886.

58. Beer AJ, Haubner R, Sarbia M, et al. Positron emission tomography using $\left[{ }^{18} \mathrm{~F}\right]$ galacto-RGD identifies the level of integrin $\alpha_{\mathrm{v}} \beta_{3}$ expression in man. Clin Cancer Res. 2006;12:3942-3949.

59. Baum RP, Kulkarni HR, Muller D, et al. First-in-human study demonstrating tumor-angiogenesis by PET/CT imaging with ${ }^{68} \mathrm{Ga}$-NODAGA-THERANOST, a high-affinity peptidomimetic for $\alpha_{\mathrm{v}} \beta_{3}$ integrin receptor targeting. Cancer Biother Radiopharm. 2015;30:152-159.

60. Iagaru A, Mosci C, Shen B, et al. ${ }^{18} \mathrm{~F}-\mathrm{FPPRGD} 2 \mathrm{PET} / \mathrm{CT}$ : pilot phase evaluation of breast cancer patients. Radiology. 2014;273:549-559.
61. van den Beucken T, Koch E, Chu K, et al. Hypoxia promotes stem cell phenotypes and poor prognosis through epigenetic regulation of DICER. Nat Commun. 2014;5:5203.

62. Shannon AM, Bouchier-Hayes DJ, Condron CM, Toomey D. Tumour hypoxia, chemotherapeutic resistance and hypoxia-related therapies. Cancer Treat Rev. 2003;29:297-307.

63. Cheng J, Lei L, Xu J, et al. ${ }^{18} \mathrm{~F}$-fluoromisonidazole PET/CT: a potential tool for predicting primary endocrine therapy resistance in breast cancer. $\mathrm{J} \mathrm{Nucl} \mathrm{Med}$. 2013;54:333-340.

64. Lopci E, Grassi I, Chiti A, et al. PET radiopharmaceuticals for imaging of tumor hypoxia: a review of the evidence. Am J Nucl Med Mol Imaging. 2014;4:365-384.

65. Wuest M, Kuchar M, Sharma SK, et al. Targeting lysyl oxidase for molecular imaging in breast cancer. Breast Cancer Res. 2015;17:107.

66. Cornelissen B, Able S, Kartsonaki C, et al. Imaging DNA damage allows detection of preneoplasia in the BALB-neuT model of breast cancer. $J$ Nucl Med. 2014;55:2026-2031.

67. Knight JC, Topping C, Mosley M, et al. PET imaging of DNA damage using ${ }^{89} \mathrm{Zr}$-labelled anti- $\gamma \mathrm{H} 2 \mathrm{AX}-\mathrm{TAT}$ immunoconjugates. Eur J Nucl Med Mol Imaging. 2015;42:1707-1717.

68. Lee SH, Meng XW, Flatten KS, Loegering DA, Kaufmann SH. Phosphatidylserine exposure during apoptosis reflects bidirectional trafficking between plasma membrane and cytoplasm. Cell Death Differ. 2013;20:64-76.

69. Krysko O, De Ridder L, Cornelissen M. Phosphatidylserine exposure during early primary necrosis (oncosis) in JB6 cells as evidenced by immunogold labeling technique. Apoptosis. 2004;9:495-500.

70. Yagle KJ, Eary JF, Tait JF, et al. Evaluation of ${ }^{18} \mathrm{~F}$-annexin $\mathrm{V}$ as a PET imaging agent in an animal model of apoptosis. J Nucl Med. 2005;46:658-666.

71. Höglund J, Shirvan A, Antoni G, et al. ${ }^{18}$ F-ML-10, a PET tracer for apoptosis: first human study. J Nucl Med. 2011;52:720-725.

72. Challapalli A, Kenny LM, Hallett WA, et al. ${ }^{18}$ F-ICMT-11, a caspase-3-specific PET tracer for apoptosis: biodistribution and radiation dosimetry. J Nucl Med. 2013;54:1551-1556.

73. Pio BS, Park CK, Pietras R, et al. Usefulness of $3^{\prime}$-[F-18]fluoro- $3^{\prime}$-deoxythymidine with positron emission tomography in predicting breast cancer response to therapy. Mol Imaging Biol. 2006;8:36-42.

74. Contractor KB, Kenny LM, Stebbing J, et al. $\left[{ }^{18} \mathrm{~F}\right]-3^{\prime}$ deoxy-3'-fluorothymidine positron emission tomography and breast cancer response to docetaxel. Clin Cancer Res. 2011;17:7664-7672.

75. Crippa F, Agresti R, Sandri M, et al. ${ }^{18}$ F-FLT PET/CT as an imaging tool for early prediction of pathological response in patients with locally advanced breast cancer treated with neoadjuvant chemotherapy: a pilot study. Eur J Nucl Med Mol Imaging. 2015;42:818-830. 